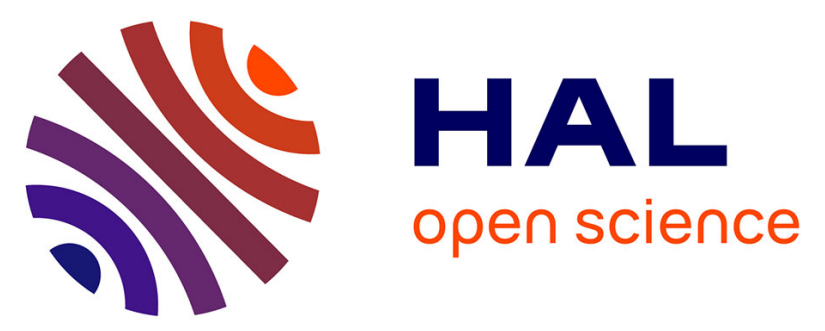

\title{
Improvement of Water Resistance of Hemp Woody Substrates through Deposition of Functionalized Silica Hydrophobic Coating, while Retaining Excellent Moisture Buffering Properties
}

\author{
Yuchao Jiang, M.A. Bourebrab, N. Sid, A. Taylor, F. Collet, S. Pretot, A.
} Hussain, M. Ansell, M. Lawrence

\section{To cite this version:}

Yuchao Jiang, M.A. Bourebrab, N. Sid, A. Taylor, F. Collet, et al.. Improvement of Water Resistance of Hemp Woody Substrates through Deposition of Functionalized Silica Hydrophobic Coating, while Retaining Excellent Moisture Buffering Properties. ACS Sustainable Chemistry \& Engineering, 2018, 6 (8), pp.10151-10161. 10.1021/acssuschemeng.8b01475 . hal-01881086

\section{HAL Id: hal-01881086}

\author{
https://hal-univ-rennes1.archives-ouvertes.fr/hal-01881086
}

Submitted on 27 Sep 2018

HAL is a multi-disciplinary open access archive for the deposit and dissemination of scientific research documents, whether they are published or not. The documents may come from teaching and research institutions in France or abroad, or from public or private research centers.
L'archive ouverte pluridisciplinaire HAL, est destinée au dépôt et à la diffusion de documents scientifiques de niveau recherche, publiés ou non, émanant des établissements d'enseignement et de recherche français ou étrangers, des laboratoires publics ou privés. 


\title{
Improvement of water resistance of hemp woody substrates through deposition of functionalised silica hydrophobic coating, whilst retaining excellent moisture buffering properties
}

Yunhong Jiang 1 , Marion A. Bourebrab2, 3 , Nadia Sid ${ }^{4}$, Alan Taylor ${ }^{4}$, Florence Collet ${ }^{5}$, Sylvie Pretot $^{5}$, Atif Hussain 1 , Martin Ansell ${ }^{1}$, Michael Lawrence ${ }^{1}$

1 BRE Centre for Innovative Construction Materials, Department of Architecture and Civil Engineering, University of Bath, BA2 7AY, UK

2 National Structure Integrity Research Centre, Granta Park, Great Abington, Cambridge, CB21 6AL, UK

3 School of Engineering, University of Edinburgh, Edinburgh, EH9 3FB, UK

4 TWI, Granta Park, Great Abington, Cambridge, CB21 6AL, UK

5 Université de Rennes, Laboratoire de Génie Civil et Génie Mécanique, Equipe Matériaux Thermo Rhéologie, IUT Génie Civil 3, rue du Clos Courtel, BP 90422, 35704 Rennes, France

*Corresponding author; e-mail: y.jiang@bath.ac.uk/yunhongjiang@yahoo.com

\begin{abstract}
This paper reports on the development of a novel treatment for hemp shiv that improves resistance to liquid water and protects hemp shiv from bio-degradation without impacting the natural ability of the shiv to buffer moisture vapour. The hydrophobic surface was produced by depositing silica nanoparticles, which were prepared by the functionalisation of silica nanoparticles with hexamethyldisilazane
\end{abstract}


(HMDS). The surface chemical composition was determined showing replacement of surface silanols on the silica nanoparticles with trimethyl groups. The specific surface area of silica nanoparticles decreased after the trimethylsilyl treatment. The surface modifications reduced the level of hysteresis between absorption and desorption isotherms and also the total amount of moisture absorbed by the silica nanoparticles. The surface of the hemp shiv was initially hydrophilic, but became hydrophobic once the material was treated, demonstrating contact angle with water of $120^{\circ}$. The results show the coating layer of functionalised silica on the hemp shiv reduced water absorption from $400 \%$ (untreated shiv) to $250 \%$. However, the moisture buffer value results showed that the coating films do not limit the access of moisture to adjacent pores in the hemp shiv and the functionalised silica coating layer retains the moisture buffering ability of hemp shiv.

\section{Keywords}

Hydrophobic coating; Nanostructure; Moisture adsorption; Hexamethyldisilazane; Renewable resources; Moisture buffer value 


\section{Introduction}

The construction industry, in common with industry in general, now has a much greater awareness of environmental and sustainability issues, and the drive from consumers to reduce the reliance on fossil based materials. Considerable attention has been focused on the utilisation of bio-based materials for construction to offer a number of benefits including thermal ${ }^{1}$, hygroscopic ${ }^{2}$ and acoustic $^{3}$ properties, whilst simultaneously delivering renewable and sustainable solutions to reduce detrimental environmental effects. Apart from timber, other bio-based materials have shown promise as construction materials, including hemp shiv, formed from the core of the hemp plant (Cannabis Sativa L.), since it has the ability to naturally regulate the indoor environment through a reduction in humidity variations as the material attracts, holds and releases moisture in response to changes in ambient conditions. This ability is due to the highly porous nature of hemp shiv and its hydrophilic character since it contains up to $44 \%$ cellulose ${ }^{2,4-6}$. These characteristics mean that hemp shiv is greatly influenced by the environment and is susceptible to decay if exposed to unsuitable environmental conditions. Therefore, it is a crucial step to modify the surface of hemp shiv in order to avoiding the problem of decay and to increase durability without detrimentally affecting the desirable moisture buffering characteristics.

One technique is to coat or chemically modify the hydrophilic surface to render it hydrophobic ${ }^{7-11}$. Approaches have been reported in the literature where nanotechnology methods have been employed to prepare multifunctional materials 
which are then deposited as coatings on plant materials ${ }^{12-14}$. This usually involves a sol-gel process to create inorganic or inorganic-organic hybrid coatings which can render a (hydrophilic) cellulose based material hydrophobic. Water sorption sites are reduced by blocking the hydroxyl groups of the cell wall through steric or chemical modification ${ }^{15-20}$. The generic chemical reactions underpinning sol-gel chemistry are well known. In these examples the assumption is that the precursor is an alkoxide, such as a silane. During hydrolysis and condensation reactions, siloxane networks are formed by precursors such as tetraethoxy silane (TEOS). These reactions provide the structural backbone of sol-gel systems. The structural evolution of sol-gel is quite complex. The different chemical paths the materials follow are influenced by acidic or basic catalysis, which has been well described by Bergna ${ }^{21}$. Significant effort has been devoted to preparing organically modified silicate materials with improved hydrophobic properties to modify the hydrophilic character of silica based materials and coatings. Surface modification of silica nanoparticles to achieve hydrophobic behaviour has been widely reported. A common route is to graft trimethyl groups to the surface via silylation reactions that replace the hydrophilic surface silanols ${ }^{22-23}$. Applications of sol-gel based materials have been reported to improve water, chemical, fire and weather resistance to wood, and also confer antibacterial properties $^{24-27}$. Liu et al. reported a superhydrophobic coating on the wood surface via a solution-immersion process ${ }^{15}$. A sol-gel method using methyltrimethoxysilane and hexadecyltrimethoxysilane was used to add a hydrophobic polysiloxane coating to wood reported by Tshabalala et $\mathrm{al}^{28}$. Tang et al. assembled silica and silver nanoparticles on the surface of wool fabric to produce super-hydrophobic property 
and antibacterial activity ${ }^{29}$. The application of sol-gel based hydrophobic coatings to bio-based materials (wood, cotton, etc.) has been discussed in the literature, but there is a general lack of information on the effect on the moisture buffering capabilities of these materials. However, the application of hydrophobic Carnauba wax particles as a non-continuous coating was reported to maintain the moisture buffering efficiency of wood by Lozhechnikova et al ${ }^{30-31}$.

The aim of this work was to develop a modification technique that increases the resistance of hemp shiv to liquid water while improving the chemical compatibility of the hemp shiv with the binder without reducing the natural ability of hemp shiv to buffer moisture vapour. This is because the presence of natural sugars on the hemp shiv surface inhibit the setting of hydraulic binders. As a first step $\mathrm{SiO}_{2}$ nanoparticles were prepared using the Stöber method. These colloidal dispersions of silica in alcohol were then functionalised to give hydrophobic behaviour. The hemp shiv were then immersed in the suspension of functionalised silica particles, withdrawn and then dried to leave a thin film of the particles on the shiv. The hydrophobicity and moisture buffer properties of the treated hemp shiv were studied by sessile drop analysis and the Nordtest test ${ }^{32}$.

\section{Experimental}

Materials

The synthesis of silica nanoparticles was carried out by using tetraethoxysilane (TEOS) (Silanes \& Silicones, Stockport, UK) as precursor, ammonia, industrial 
methylated spirit (IMS, 99\% ethanol, 1\% methanol) (Sigma-Aldrich, Gillingham, UK), and water which was deionised in-house. The functionalising agent, hexamethyldisilazane, was also purchased from Silanes \& Silicones. The hemp shiv were provided by Cavac Biomateriaux (Cavac, Sainte-Gemme-La-Plaine, France). The chemical and physical characteristics of the hemp shiv materials used are as reported by Jiang et $\mathrm{al}^{33}$.

Synthesis and modification of $\mathrm{SiO}_{2} \mathrm{NPs}$

The Stöber process was followed in order to synthesise silica nanoparticles, at room temperature ${ }^{34}$. First, a solution containing appropriate quantities of IMS, ammonia and deionised water was stirred for 5 minutes to ensure complete mixing. Separately the TEOS was mixed with IMS and the mixture was then added to the first solution. The reaction proceeded at ambient temperature for $48 \mathrm{~h}$ according to concentrations of reactants, similarly to the protocol followed by Bourebrab et al. ${ }^{19}$. The formulation reached $4.3 \mathrm{wt} \%$ silica on completion of the reaction. The silica nanoparticles are referred to as TSS4.

To functionalise the silica a reaction with hexamethyldisilazane was undertaken in the parent suspension by heating at $65^{\circ} \mathrm{C}$ for $18 \mathrm{~h}$ so that the silanols present on the surface of the silica nanoparticles would react with the silazane by condensation. The functionalised silica is referred to as TSS4T1. 
To prepare for the hydrophobic treatment of the hemp shiv, the hemp shiv was oven dried at $90^{\circ} \mathrm{C}$ for one hour prior to coating. The shiv was then immersed in the TSS4T1 aqueous suspension for $1 \mathrm{~min}$ with constant mixing. The coated hemp shiv was then shaken to remove any visible liquid which would have remained on the surface of the shiv, and then the bio-materials were oven dried at $90^{\circ} \mathrm{C}$ for one hour.

Sessile drop assessment

The static sessile drop method was used to determine wetting behaviour of the samples. The materials and methods used are as reported by Bourebrab et al ${ }^{19}$. Three to ten droplets of deionised water of approximately $2 \mu \mathrm{L}$ were placed onto the samples. An image of the droplets was captured after waiting one or two seconds for the drop to reach equilibrium before taking a measurement, thus allowing key dimensions to be measured.

\section{Materials Characterisation}

The morphology of the surface coating was characterised using a scanning electron microscope (SEM) (JEOL SEM-6480LV, Tokyo, Japan) and a field emission scanning electron microscope (FE-SEM) (JEOL FESEM6301F). The materials and methods used are as reported by Jiang et $\mathrm{al}^{33}$. TSS4T1 were also deposited on copper grids for transmission electron microscopy (TEM) (JEOL-2100 Plus) observation, and the accelerating voltage was $200 \mathrm{kV}$. The thickness of coating layers and the internal surface of hemp shiv were characterised by a dual beam FEI Quanta 3D scanning electron microscope (FIB-SEM) with a platinum deposition. The surface areas and 
the pore size distributions of the samples were calculated from nitrogen adsorptiondesorption isotherms at $77 \mathrm{~K}$ using the BET method (3Flex, UK). Size measurement of the silica particles was performed using dynamic light scattering (DLS) on a Malvern Zetasizer Nano-S (Malvern Instruments, Malvern, UK), at room temperature, via a back-scattering method. FTIR analysis of treated and untreated hemp shiv was carried out by using a PerkinElmer FTIR spectrometer model Frontier. Transmittance spectra were recorded in an Attenuated Total Reflection (ATR) mode and collected with $2 \mathrm{~cm}^{-1}$ resolution, and 10 scans were accumulated for each spectrum in the range $4000-600 \mathrm{~cm}^{-1}$. For this analysis the silica suspension was dried, and crushed to break down the aggregates. The same amount of sample was ground with a 1:300 dilution of $\mathrm{KBr}$ to produce pellets. Transmittance spectra were recorded in transmission and collected with $2 \mathrm{~cm}^{-1}$ resolution, and 10 scans were accumulated for each spectrum in the range $4000-600 \mathrm{~cm}^{-1}$.

Study of adsorption and desorption behaviour of water vapour on TSS4 and TSS4T1 The adsorption and desorption of water vapour were investigated on TSS4 and TSS4T1 using a Surface Measurement Systems dynamic vapour sorption apparatus (DVS, Surface Measurement Systems, UK). The materials and methods used are as reported by Hill et $\mathrm{al}^{35}$.

\section{Water absorption test}

The hemp shiv samples were placed in water at room temperature without applying any additional force to immerse them. The hemp shiv pieces floated to the surface as 
their density was lower than water. Therefore, the majority of the water absorption took place through the capillary behaviour in the hemp shiv samples. The samples were taken out of water at specified time intervals, and the mass readings were taken within 30 seconds of removal using a balance with an accuracy of $\pm 0.1 \mathrm{mg}$. Any water visible on the surface of hemp shiv samples was shaken off before the measurement. The water absorption was calculated by the mass change (\%) between the initial mass and the mass after 24 hours of water absorption. The measurements were performed in triplicate and the average reading was reported ${ }^{36}$.

Moisture buffering analysis

In order to evaluate the effectiveness of moisture buffering, the Practical Moisture Buffer Value (MBV) in $\mathrm{g} / \mathrm{m}^{2} . \% \mathrm{RH}$ was calculated. The moisture buffering experiments were performed in accordance with the Nordtest method ${ }^{32}$. MBV defines the amount of moisture transported into or out of a material per unit of open surface area, during a specified period of time, when the material is exposed to cyclic variations in relative humidity ( 8 hours at 75\% RH, followed by 16 hours at $33 \% \mathrm{RH}$ ). Samples were put in watertight cylindrical containers, $10 \mathrm{~cm}$ in diameter, open at the top. Containers were chosen to be higher than the penetration depth. Full details of the materials and methods used are as reported by Collet et $\mathrm{al}^{37}$.

\section{Results and Discussion}

Characterisation of the silica NPs and the functionalised silica NPs 
TEM images of the Stöber silica before and after functionalisation are shown in Fig 1.

Fig. 1A shows the TSS4 nanoparticles had formed irregular agglomerations. Typically, the size of the TSS4 particle is between 15-30 nm. Fig. 1B shows that the TSS4T1 nanoparticles have a similar particle size to the untreated primary silica nanoparticles (TSS4). No distinct coating layers from the trimethylsilylation were observed on the outside of the TSS4T1 nanoparticles because the silylation will generate a surface assembled monolayer, which is likely to be less than $1 \mathrm{~nm}$. Overall, silica nanoparticles did not exhibit notable changes in appearance after modification. The particles are spheroidal with both major and minor axis diameters in the range of 15-30 nm.

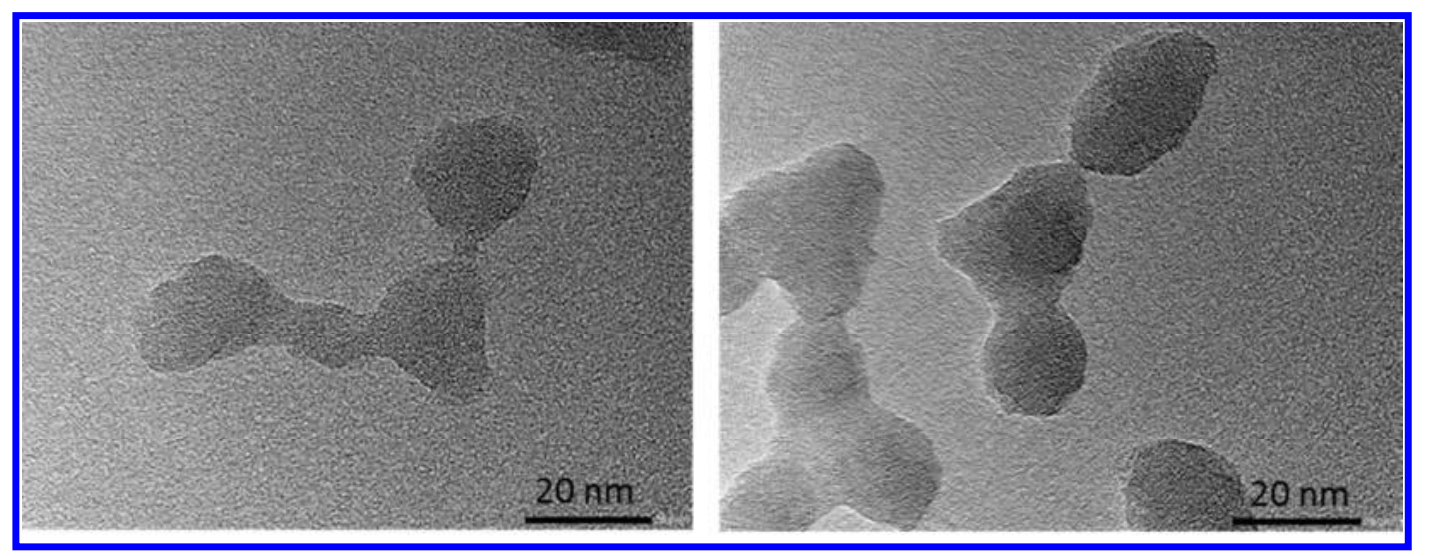

(A)

(B)

Figure 1: TEM images of the TSS4 (A) and the TSS4T1 (B)

Suspensions of both TSS4 and TSS4T1 nanoparticles were analysed by Dynamic Light Scattering (DLS), in order to provide estimates of their hydrodynamic sizes. The average measured diameters for the TSS4 and TSS4T1 nanoparticles were 22.6 and $20.8 \mathrm{~nm}$, respectively, in Table 1. Fig. 2 also shows that the two suspensions had 
similar size distributions. The size distribution of silica nanoparticles shifted to slightly smaller values after surface modification. The corresponding polydispersity indexes (PDI) for DLS measurement are also reported in Table 1. Stetefeld et al reported that a PDI of $\sim 0.1$ indicates a monodisperse system ${ }^{38}$. This indicates that both suspensions are not monodispersed and there are some aggregates around a few micrometres present in both suspensions of TSS4 and TSS4T1, as shown in Fig. 2. The TEM diameter of the samples is similar to the size measured by DLS. The inserted images in Fig. 2 show that the TSS4 and TSS4T1 suspensions were transparent with a slightly blue haze due to Rayleigh scattering. No sedimentation of either TSS4 or TSS4T1 suspension was observed after two years, which showed that both suspensions have excellent colloidal stability.

Table 1. The z-average diameters and polydispersity index (PDI) obtained by Zetasizer Nano

\begin{tabular}{cccccc}
\hline Samples & $\mathrm{T}\left({ }^{\circ} \mathrm{C}\right)$ & Z-Ave $(\mathrm{nm})$ & Std Dev & PDI & Std Dev \\
\hline TSS4 & 25 & 22.6 & \pm 0.17 & 0.3 & \pm 0.002 \\
TSS4T1 & 25 & 20.8 & \pm 0.39 & 0.4 & \pm 0.013 \\
\hline
\end{tabular}

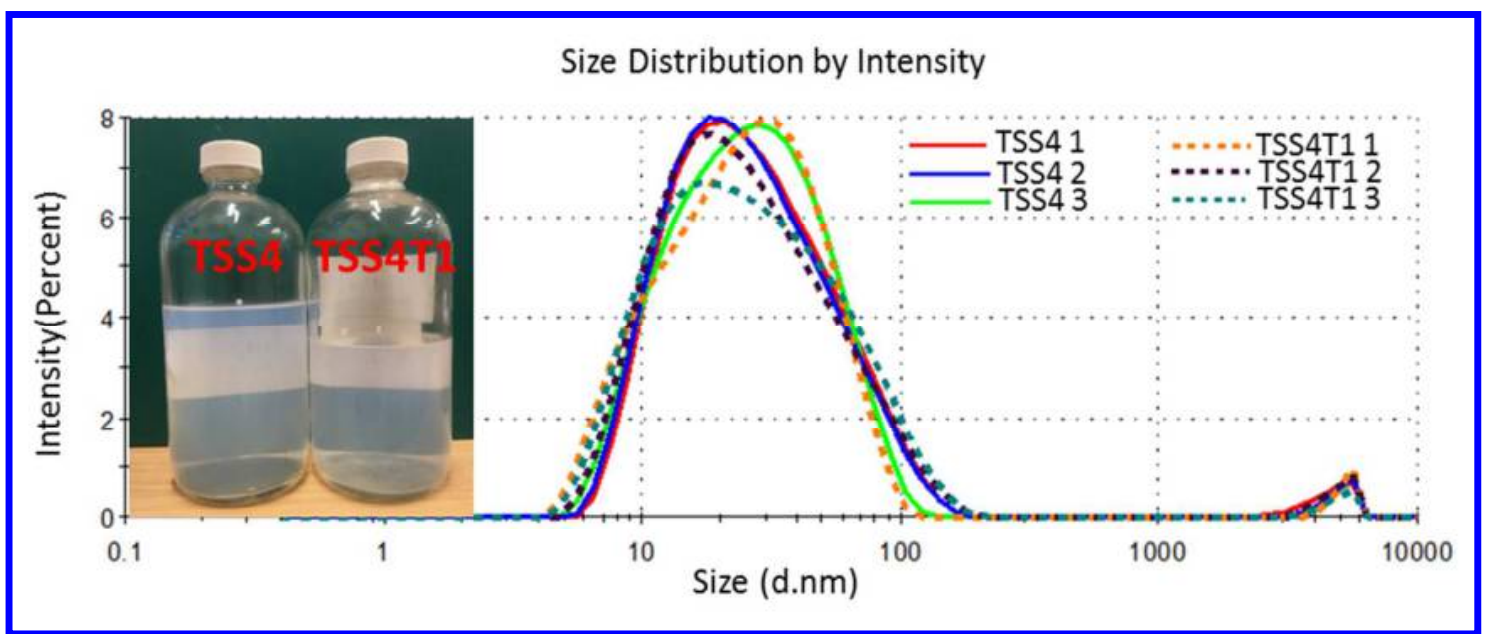


Figure 2: The intensity size distribution of the silica NPs and the functionalised silica NPs versus particle diameter in nanometres. The different colours represent repeat measurements of the same sample. The inserts are the photo images of the sample suspension.

The specific surface areas and the parameter C values of the BET equation for TSS4 and TSS4T1 are shown in Fig. 3 and Table 2. They both show typical type IV isotherms according to the IUPAC classification ${ }^{39-40}$, which is characteristic of mesoporous materials. Both the values decreased after the surface modification. Since the parameter $\mathrm{C}$ is related to the affinity of the solid with the adsorbate (the $\mathrm{N}_{2}$ molecules) and so to the heat of adsorption. The higher the value of $\mathrm{C}$, the higher the interaction between adsorbate and surface of sample ${ }^{41}$. TSS4T1 has a lower value for C (38) in the BET equation and TSS4 has a higher value for C (143), indicating a reduction in the strength of the interaction between the nitrogen molecules and the molecular surface. This can be explained by the ability of the TMS groups to change the silica surface to a nonpolar surface from a polar surface ${ }^{42}$. The pore size distributions of the samples before and after the modification are shown in Fig.3 and Table 2. The increase in pore diameter as a result of the surface modification is 0.74 nm. 


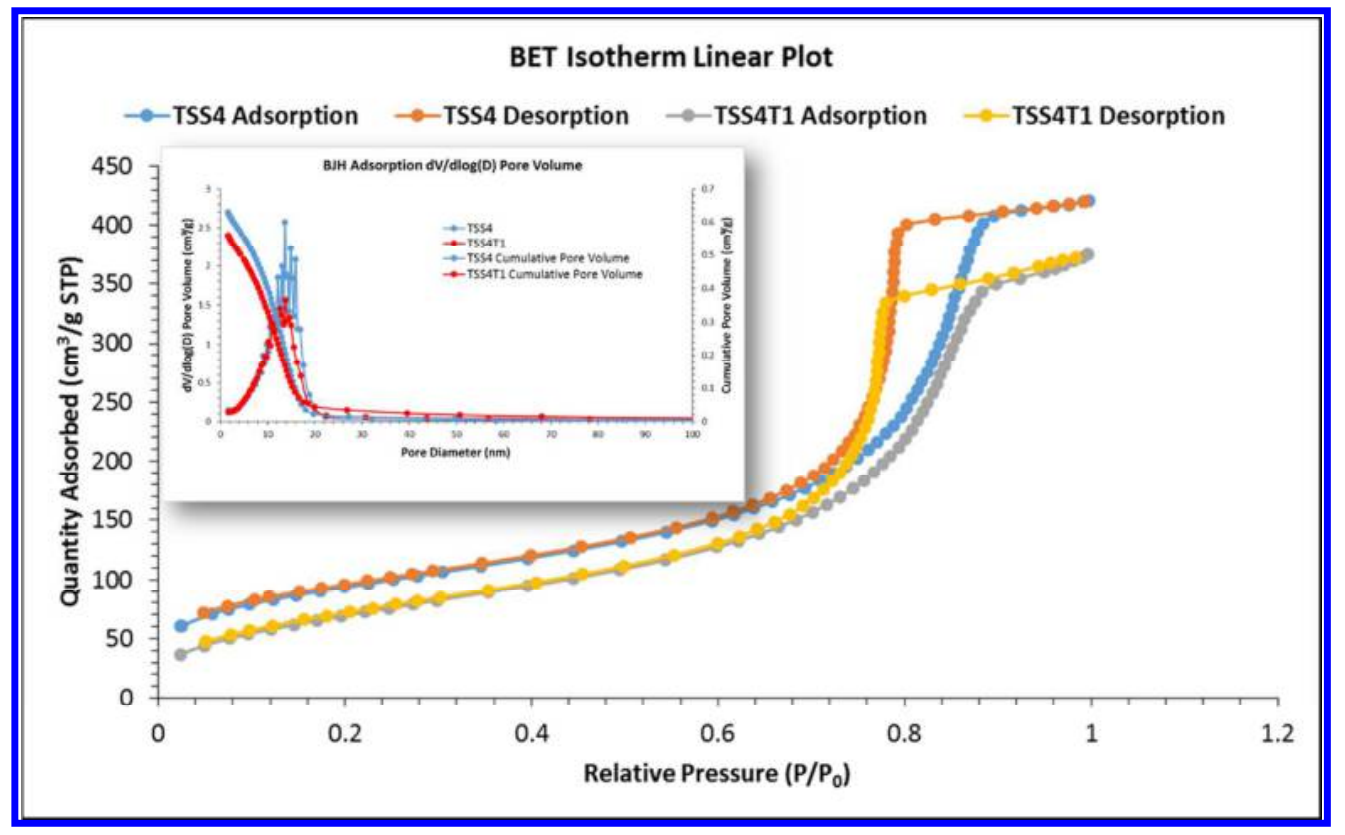

Figure 3: $N_{2}$ adsorption-desorption isotherms of silica (TSS4) and functionalised silica (TSS4T1). The insert is the BJH pore distribution of both samples.

Table2: Surface structure parameters of TSS4 and TSS4T1

\begin{tabular}{ccccc}
\hline Sample & Surface Area & Pore & C value & Average \\
& $\left(\mathrm{m}^{2} / \mathrm{g}\right)$ & Volume & & Pore \\
& & $\left(\mathrm{cm}^{3} / \mathrm{g}\right)$ & & Diameter \\
& & & & $(\mathrm{nm})$ \\
& & & & 7.82 \\
TSS4 & $330.78 \pm 2.37$ & 0.647 & 143.84 & 8.56 \\
\hline
\end{tabular}

Fig. 4 shows the FTIR spectra of the silica nanoparticles pre- and posttrimethylsilylation to confirm whether the hydrophobic reagent had been grafted on to the surface of the silica nanoparticles. Both spectra have a very strong absorption band at $1064 \mathrm{~cm}^{-1}$ and two medium intensity bands at $963 \mathrm{~cm}^{-1}$ and $795 \mathrm{~cm}^{-1}$ which 
are as expected from the silica in the sol-gel process ${ }^{43}$. The signal at $3448 \mathrm{~cm}^{-1}$ is due to free $\mathrm{OH}$ group and the signal at $1654 \mathrm{~cm}^{-1}$ is due to the antisymmetric vibration of Si-OH. The bending and stretching vibrations of the Si-O-Si bond are represented in the two absorption peaks near $1064 \mathrm{~cm}^{-1}$ and $795 \mathrm{~cm}^{-1}$. The absorption peak at 963 $\mathrm{cm}^{-1}$ is associated with $\mathrm{Si}-\mathrm{OH}$ group stretching vibrations. Whilst the FTIR spectra of TSS4 and TSS4T1 exhibit many similarities, two additional absorption peaks appear for TSS4T1, representing the $\mathrm{Si}-\mathrm{CH}_{3}$ stretching and bending vibrations at $845 \mathrm{~cm}^{-1}$ and $760 \mathrm{~cm}^{-1} 44-45$. The band intensity of the free hydroxyl band and the hydrogen bonded hydroxyl groups are significantly decreased for the TSS4T1 sample compared with the TSS4 sample. The spectra shown in Fig. 4 demonstrate the successful silylation of the surface of the silica particles

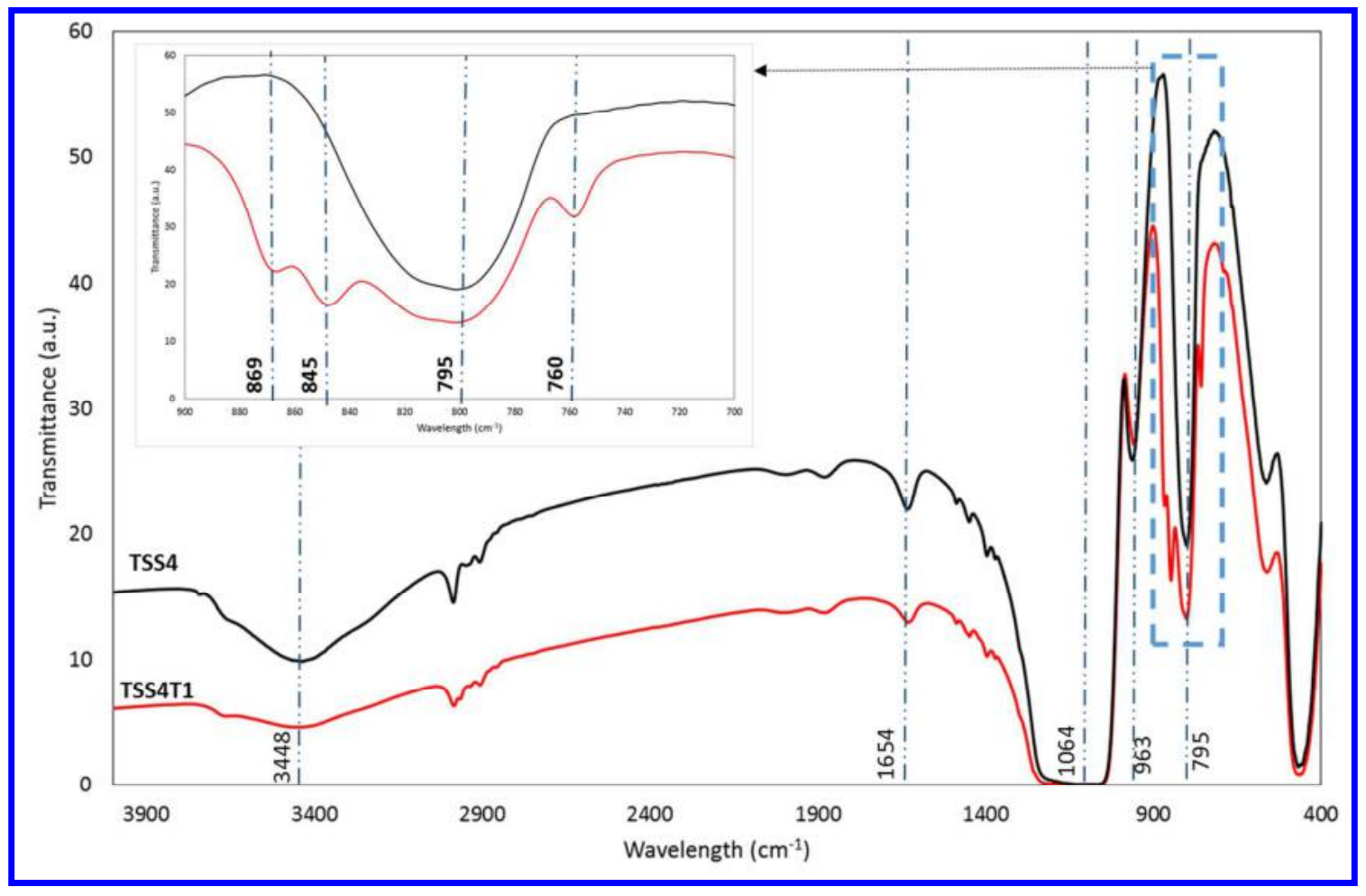


Figure 4: FTIR spectra of TSS4 and TSS4T1 between 4000 and $400 \mathrm{~cm}^{-1}$ at room temperature. The insert is the magnified wavelength between $700 \mathrm{~cm}^{-1}$ and $900 \mathrm{~cm}^{-1}$.

\section{Water vapour sorption study on TSS4 and TSS4T1}

Fig. 5A shows the sorption isotherms of water vapour on TSS4 and TSS4T1 samples. The absolute hysteresis (obtained by subtracting the adsorption from desorption isotherm loop moisture content values) is given in Fig. 5B. The type of water vapour sorption according to the IUPAC classification for TSS4 is a type IV isotherm, whereas it is a type $\mathrm{I}(\mathrm{b})$ isotherm for TSS4T141. Type I isotherms are seen in microporous solids which have relatively small external surfaces. The classification of Type I isotherms can be categorised further as Type I(a) which represents microporous materials with predominantly narrow micropores less than 1nm wide, and Type $I(b)$ which represents those materials with a larger range of pore sizes from wider micropores to narrow mesopores. Type IV isotherms are typically found in mesoporous adsorbents. In mesopores the adsorption behaviour is driven by the adsorbent-adsorptive interactions and the interactions between molecules when in the condensed state $^{39}$. In this case, although the TSS4 and TSS4T1 have a similar pore size distribution, the interactions between the adsorbent-adsorptive have been changed due to the presence of TMS group on the surface of TSS4T1. The amount of water vapour adsorbed on the samples at the same relative pressure decreases significantly after surface modification, especially at higher RH levels. There is a significant reduction in hysteresis between TSS4 and TSS4T1 in the upper part of the hygroscopic range. The reduction of water vapour adsorption and hysteresis on the 
TSS4T1 sample is attributed to the superficial hydroxyl groups $(-\mathrm{OH})$ being replaced by silazane (Si-N) groups, which is also evident in the FTIR curves (Fig. 4). The water vapour isotherm for the TSS4T1 sample still shows a clear knee at lower RH levels, and therefore does not display the typical type III isotherm characteristics, which would have been expected where water adsorption occurs on a hydrophobic surface $^{42}$. This may be because TSS4T1 has many active sites for water vapour adsorption despite the silylation which is indicative of residual silanols, a finding which is supported by the FTIR analysis. The absence of capillary condensation of water is also of note in the TSS4T1 samples, as can be seen in Fig.5, where the TSS4T1 isotherm shows minimal mass increase and no measurable hysteresis, in contrast to TSS4. The possible reason is that the increased hydrophobicity decreases surface energy of pore walls and thus decreases the tendency for capillary condensation. 


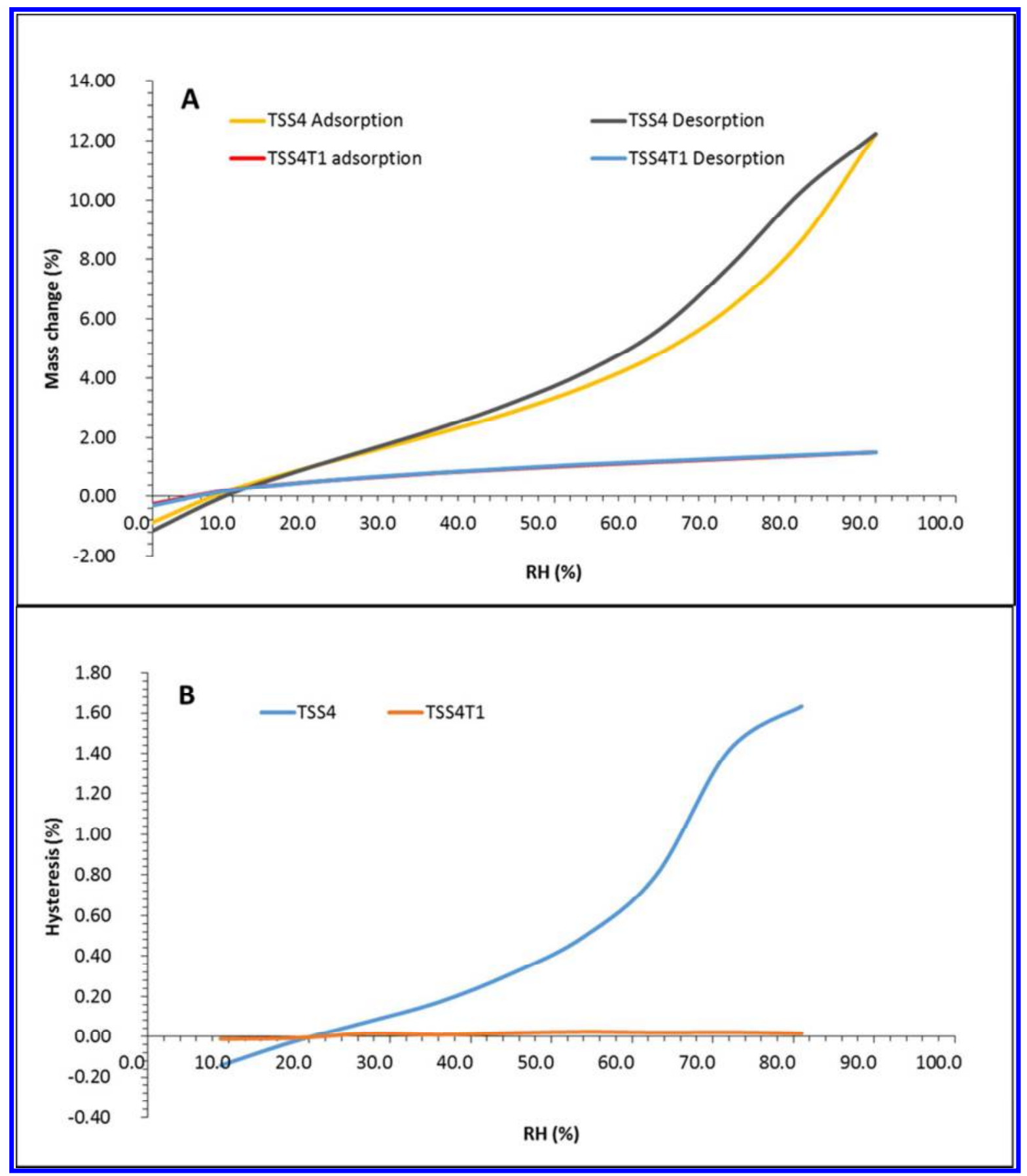

Figure 5: Water vapour adsorption-desorption isotherms of TSS4 and TSS4T1 (A) and absolute hysteresis plotted as a function of $R H$.

Characterisation of the hemp shiv and coated hemp shiv 
The surface morphologies of the hemp shiv samples were observed by FESEM. Fig. 6 shows characteristic views of the raw hemp shiv and the dip-coated hemp shiv. The raw hemp shiv shown in Fig. 6, A and B, exhibits a microscale cell structure (pits) with a typically smooth surface. The diameter of pits is around $2 \mu \mathrm{m}$. Fig. $6, \mathrm{C}$ and D show even coating layers of TSS4T1, together with some agglomerated nanoparticles. The coating is cracked at the edges of the pits. The coating layers masked the anatomical details, and the pits are in some cases filled in with TSS4T1 but not completely occluded by the particles. The surface of the coating is very rough according to Fig. 6, E and F. These particles arise from the assembly and aggregation of the silica nanoparticles on the surface of the hemp shiv. The particle size of modified silica were around $20 \mathrm{~nm}$ according to the TEM data (Fig.1). There are a great number of voids among these silica nanoparticles. The voids serve to create the conditions required for a hydrophobic coating, as they are able to repel water and trap air. 


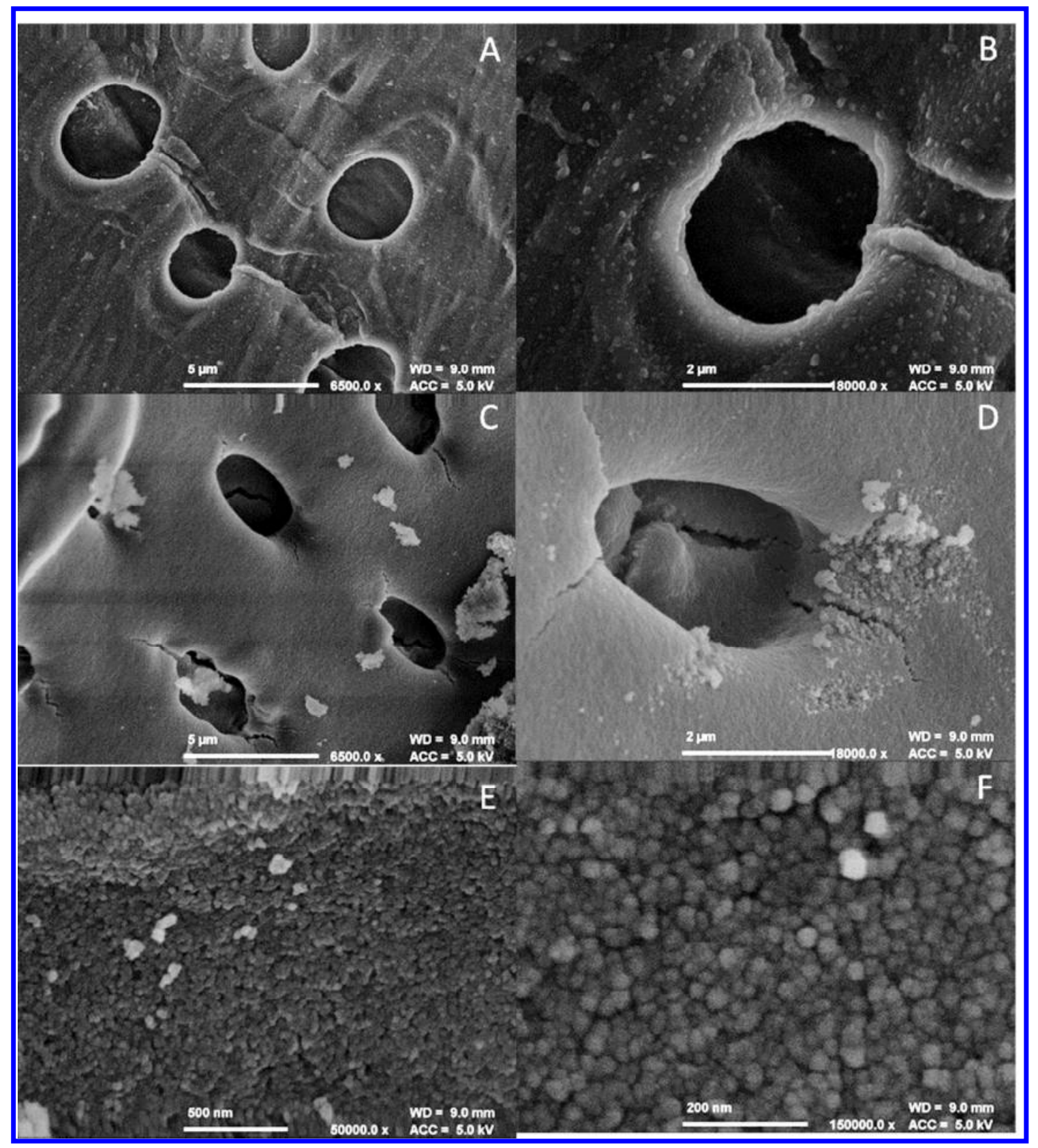

Figure 6: Field emission SEM micrographs of (A) and (B) untreated hemp shiv (C), (D), (E)

$$
\text { and (F) dip-coated hemp shiv }
$$

Fig.7 shows 'slice and view' on dip-coated hemp shiv using the FIB-SEM. Fig. 7A images a $25 \mu \mathrm{m}$ diameter hole cut using an ion beam. Fig. 7B and $7 \mathrm{C}$ reveal the hidden layered structure of the coating layer. The modified silica coated on the 
surface of hemp shiv with multiple layers has a thickness between 130 and $160 \mathrm{~nm}$. A sputtered gold coating was also applied to increase electrical conductivity for imaging and platinum deposition for protection of samples is also visible. Fig. 7D shows that the cell lumens were empty, and a thin layer of silica coating with a thickness of $65 \mathrm{~nm}$ was observed on the surface of the void cell wall. It indicates that the modified silica not only coated the exterior of the hemp shiv but also penetrated into the hemp shiv and was deposited onto the internal cell walls.

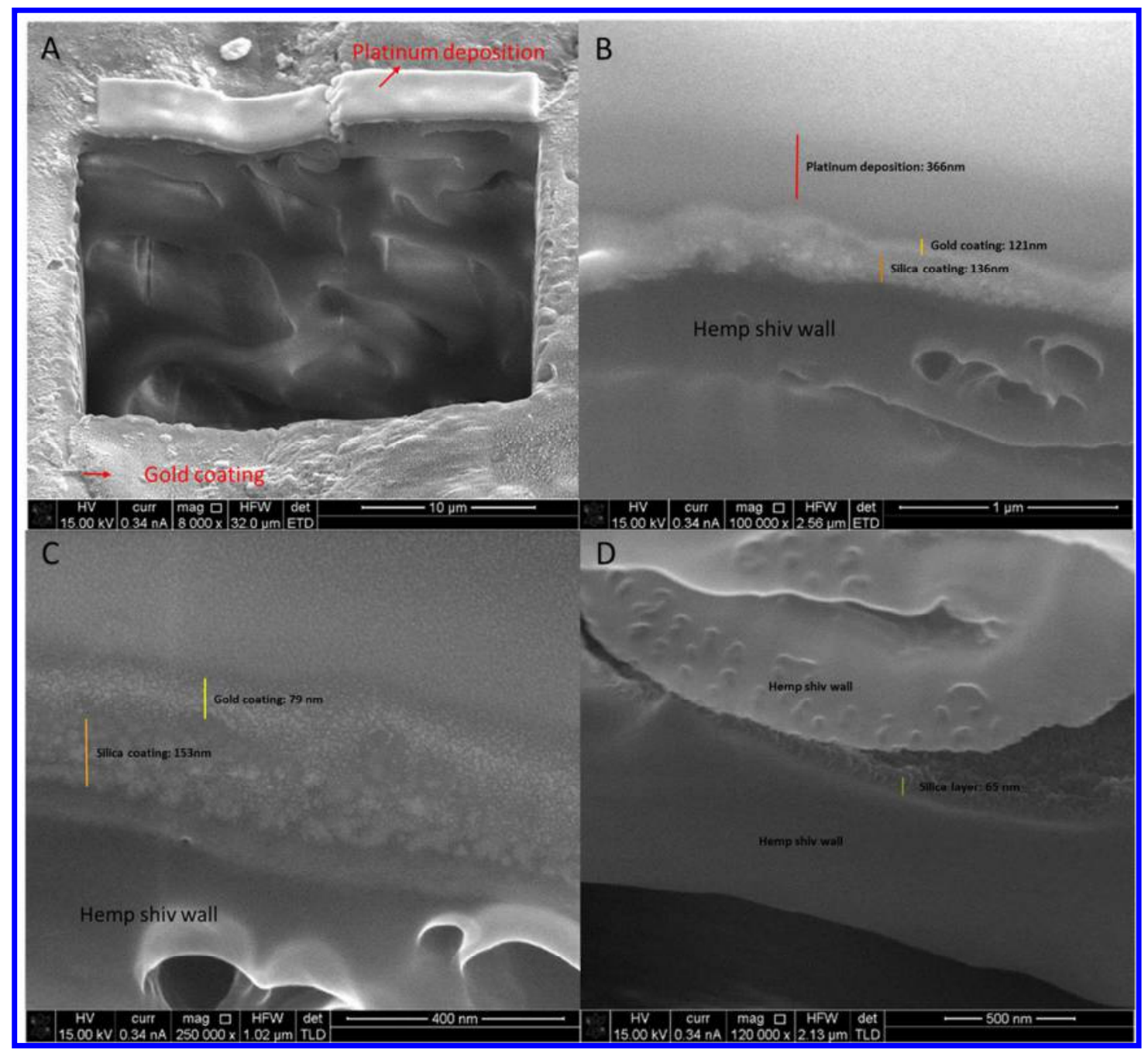


Figure 7: FIBSEM cross-section micrographs of dip-coated hemp shiv. (A) the surface of dipcoated hemp shiv with gold coating and platinum deposition as viewed using a SEM. The dark region in the centre of the image represents a microscopic hole where material has been machined out by a beam of ions. (B) and (C) magnified views of the previous image reveals the hidden layered structure of a coating layer and clear silica and gold nano-films. (D) voids in the hemp shiv are more clearly shown in this cross-sectional image. A very thin coating layer was observed just above the hemp shiv cell wall.

Fig. 8 shows typical FTIR spectra in an ATR mode for the control and coated hemp shiv samples. The chemical composition of hemp shiv is mainly cellulose, hemicellulose and lignin. Fig. 8 shows a raw hemp shiv FTIR spectrum with broad bands at $3448 \mathrm{~cm}^{-1}$ (-OH stretch from polysaccharides), $2918 \mathrm{~cm}^{-1}$ (-C-H stretch in methyl and methylene groups from polysaccharides), $1733 \mathrm{~cm}^{-1}(\mathrm{C}=\mathrm{O}$ stretch in unconjugated ketone, carbonyl and ester group from hemicellulose), $1605 \mathrm{~cm}^{-1}$ (Aromatic vibration, $\mathrm{C}=\mathrm{O}$ stretch), $1417 \mathrm{~cm}^{-1}\left(\mathrm{CH}_{2}\right.$ bending, $\mathrm{C}=\mathrm{C}$ stretching in aromatic group from lignin), $1369 \mathrm{~cm}^{-1}$ ( $\mathrm{CH}_{2}$ bonding from polysaccharides), 1319 $\mathrm{cm}^{-1}$ (C-H vibration from cellulose) and $1241 \mathrm{~cm}^{-1}(\mathrm{C}=$ stretch from lignin and xylan). The fingerprint region is dominated by bands at approximately $1050-1030 \mathrm{~cm}^{-1}$ attributed to $\mathrm{C}-\mathrm{O}$ deformation from various polysaccharide vibrations ${ }^{46-48}$. The characteristic peaks of the dip-coated hemp shiv are shown in Fig. 8. It can be seen that the absorption peaks at 795, 845, 963 and $1064 \mathrm{~cm}^{-1}$, are in good agreement with the observed absorption peaks from the pure coating material analysed in Fig. 4. As reported in the literature, the peak at $1064 \mathrm{~cm}^{-1}$ represented the asymmetric stretching of the oxygen atoms of two adjacent $\mathrm{Si}-\mathrm{O}-\mathrm{Si}$ units. The bending vibrational 
mode of Si-O-Si units is seen in the broad peak at $795 \mathrm{~cm}^{-1}$ and the presence of $\mathrm{Si}-\mathrm{OH}$ group stretching vibrations create the peak at $963 \mathrm{~cm}^{-1} 49-51$. The band at $3448 \mathrm{~cm}^{-1}(-$ $\mathrm{OH}$ stretch), seen on the raw shiv, has almost disappeared on the coated shiv. This is attributed to the replacement of the surface $\mathrm{OH}$ groups with trimethyl $\left[-\left(\mathrm{CH}_{3}\right)_{3}\right]$ groups $^{22}$. The FTIR data confirms that the functionalised silica NPs coated on hemp shiv significantly alter the surface chemistry.

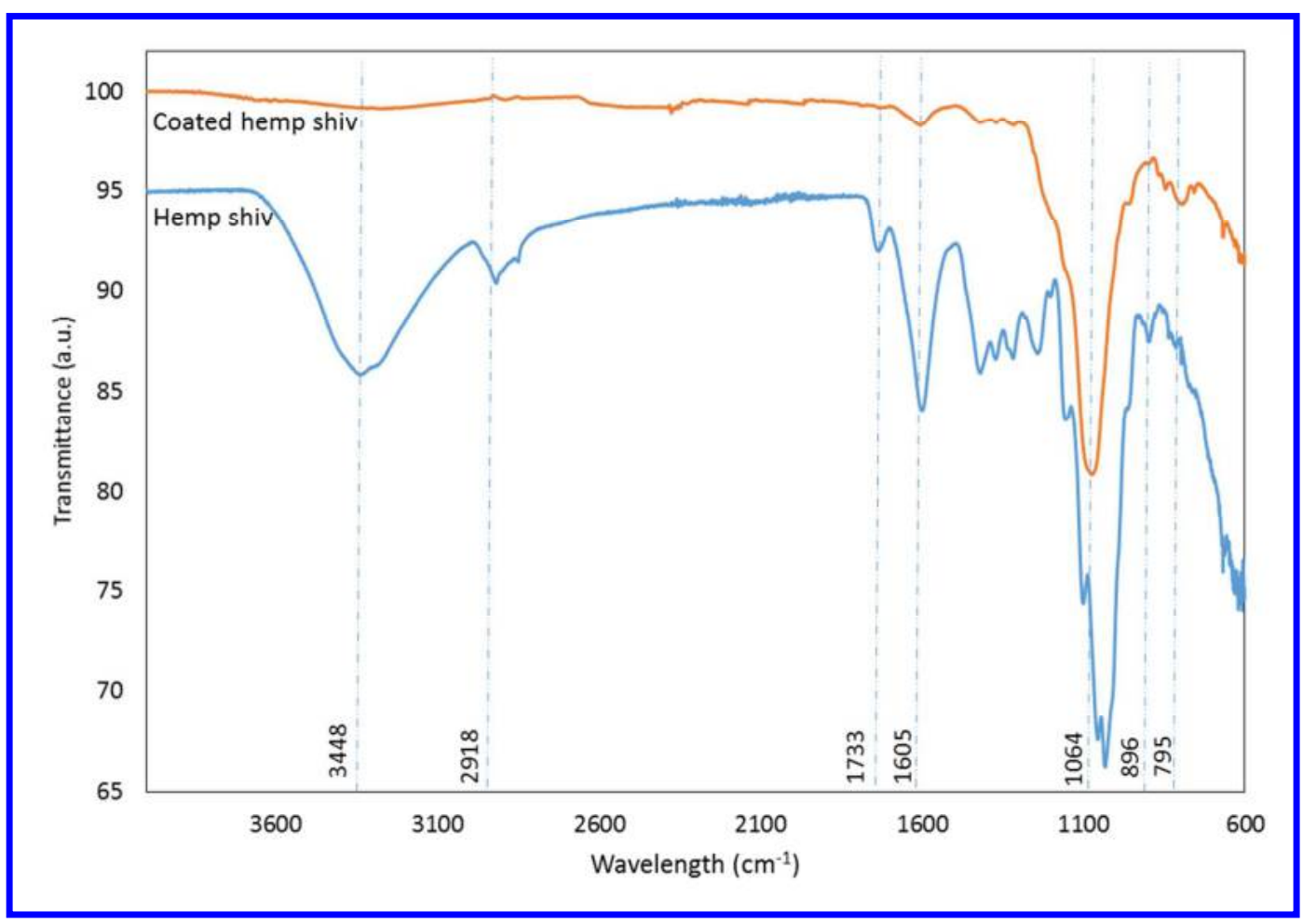

Figure 8: FTIR spectra of the control hemp shiv and the dip-coated hemp shiv

The composition of the untreated and treated hemp shiv was determined by energy dispersive spectroscopy (EDX) analysis. Fig 9A clearly shows the main peaks detected for hemp shiv were carbon and oxygen in the EDX spectrum plus Au peak, from the sputtered coating for SEM preparation, dip-coated hemp shiv also shows a 
high silicon content attributable to the TSS4T1 as shown in Fib.9B. By considering the FTIR data in conjunction with the SEM/EDX data, it appears that the modified silica coating is linked to the cell wall. In order to confirm this, further studies utilising solid state nuclear magnetic resonance spectroscopy are required on the link between the silica nanoparticles and cell wall components

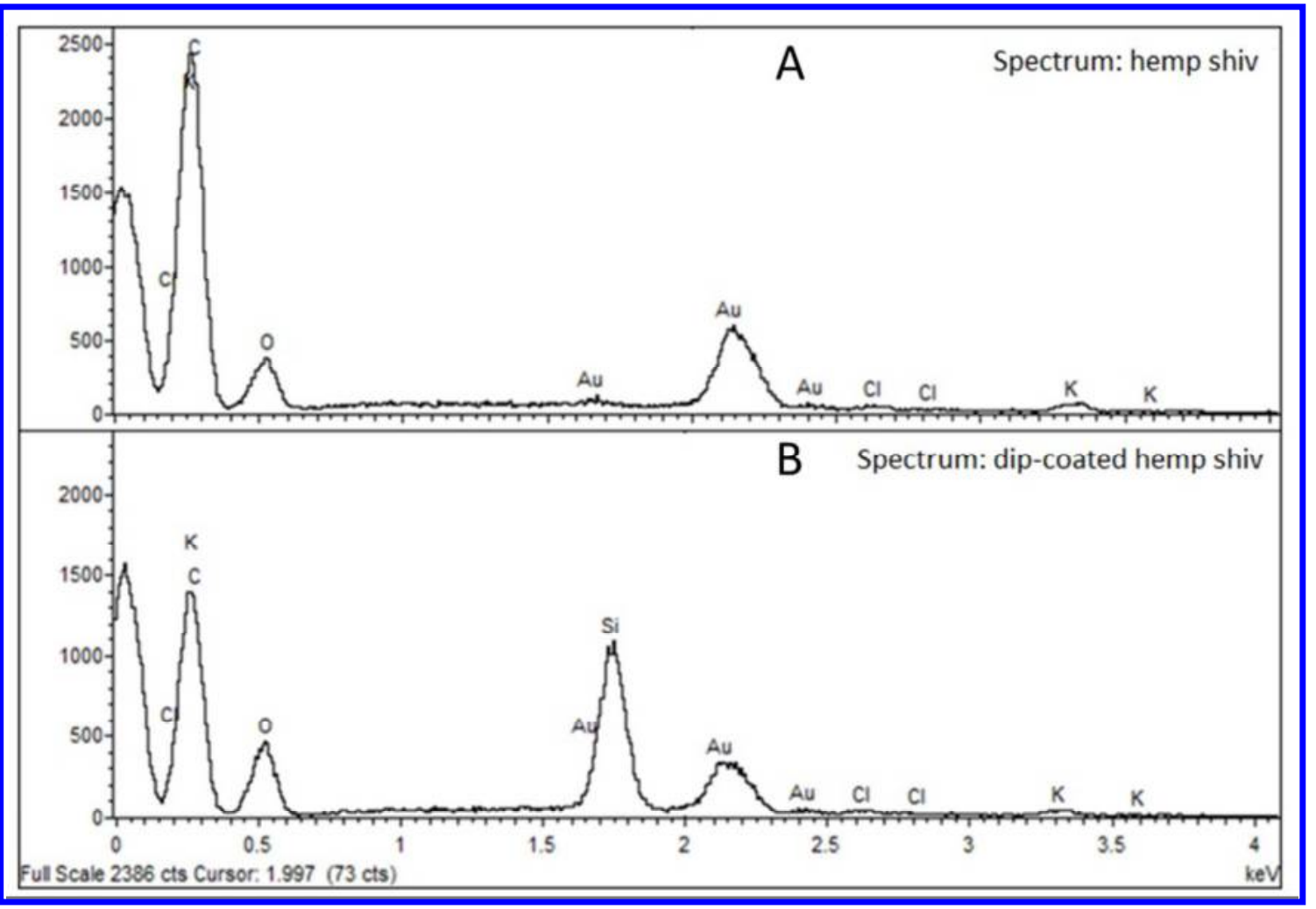

Figure 9: EDX spectra of $(A)$ untreated hemp shiv and (B) dip-coated hemp shiv

Water contact angle and water sorption

In order to identify a change in the surface property of hemp shiv after TSS4T1 coating, the water contact angles of hemp shiv and coated hemp shiv were measured. Fig. 10A shows the hemp shiv has a hydrophilic property with a water contact angle of approximately $65.0^{\circ} \pm 0.9^{\circ}$. When the surface of hemp shiv was changed to be 
hydrophobic as a result of treatment with TSS4T1, the water contact angle increased to $120.0^{\circ} \pm 1.2^{\circ}$, which is much higher than that of the raw hemp shiv. The readings reported were the average of five measurements. The water contact angle of coated hemp shiv was re-measured after immersing the shiv in DI water for 24 hours with constant stirring in the beaker. The resulting water contact angle of $115.0^{\circ} \pm 0.8^{\circ}$ as shown in the supporting document, is only marginally lower that that achieved in the first set of measurements, confirming the robustness of the coating. The equipment used has a reproducibility of $\pm 2^{\circ}$.

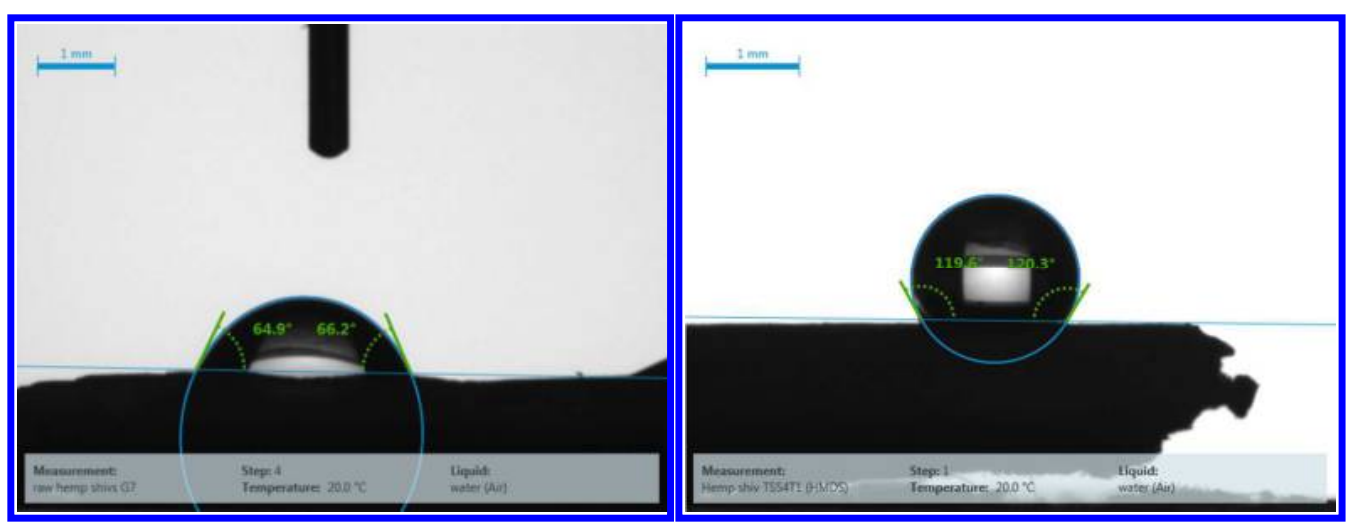

(A)

(B)

Figure 10: Water contact angle of raw hemp shiv (A) and coated hemp shiv (B). Note: Image is one of five measurements

The hydrophobic silica coating acts as a barrier to liquid water to reduce the water sorption. Fig. 11 shows the rate of distilled water absorption for raw hemp shiv and hemp shiv coated with TSS4T1 when held at room temperature over a period of $24 \mathrm{~h}$. The raw hemp shiv had a maximum water absorption of approximately $400 \%$ increase in mass, and absorbed more than half of this amount within the first few 
minutes of dipping. The highly porous structure and hydrophilic characteristics of hemp shiv are responsible for the water absorption performance. A functionalised silica coating layer on the hemp shiv reduced the water absorption from $400 \%$ for the untreated shiv to $250 \%$ for the treated shiv, which is $150 \%$ less than the uncoated shiv. This reduction in water absorption is due to a large decrease in the absorption of water within the cell walls, with the remaining water being held within the capillaries of the highly open structure. This demonstrates that treating the shiv with functionalised hydrophobic silica provides enhanced water resistance and hence resistance to bio-decay is assumed.

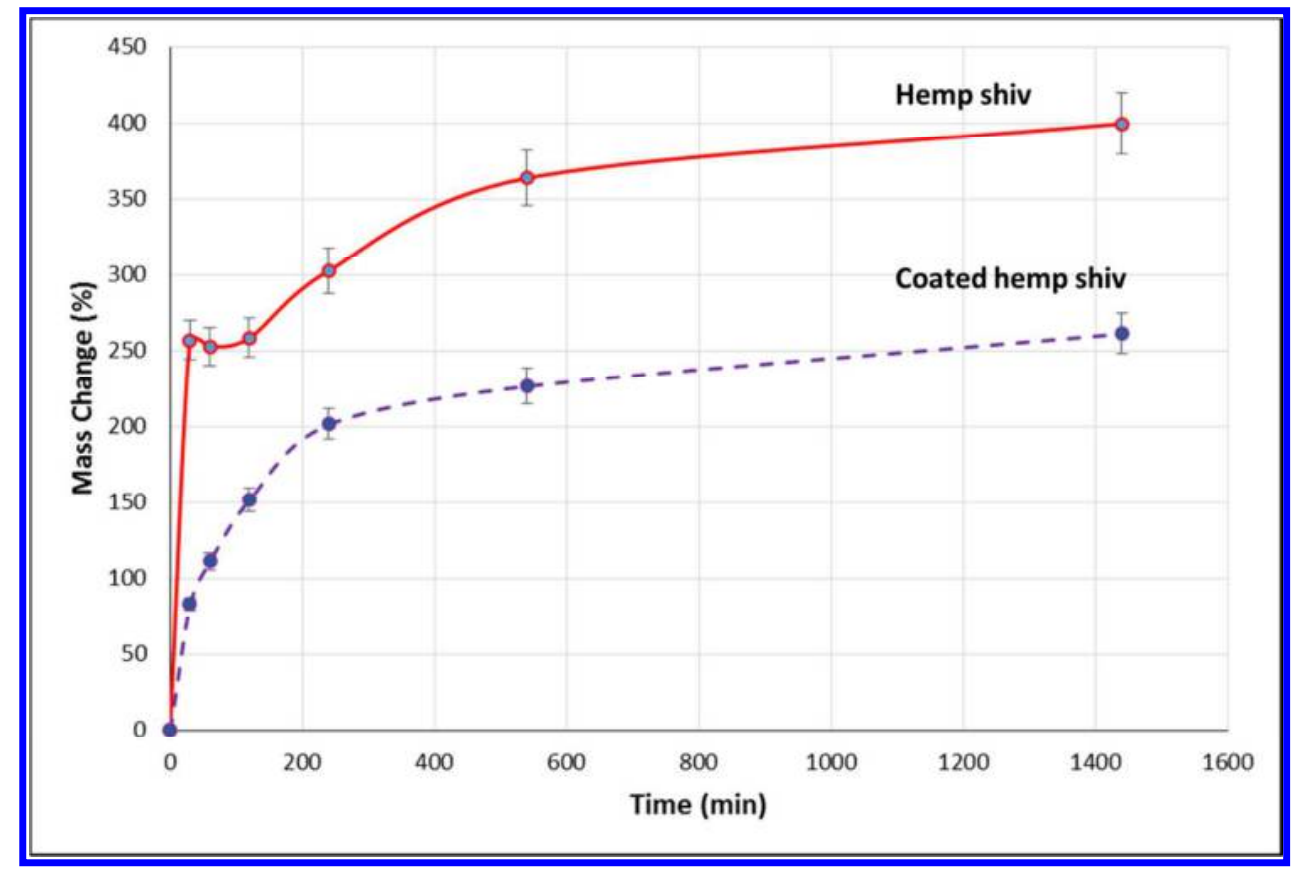

Figure 11. Dependence of water absorption on time for hemp shiv and coated hemp shiv

Moisture sorption analysis 
Moisture buffering is an energy-efficient material characteristic which enables the absorption, storage and release of moisture, which in turn can regulate the indoor environment by avoiding extremes of humidity and reducing excessive variations. It is a very important parameter for building materials. The MBV values for the hemp shiv and coated hemp shiv are shown in Fig. 12. The coated hemp shiv shows a MBV value of $2.25 \mathrm{~g} /\left(\mathrm{m}^{2} . \% \mathrm{RH}\right)$, while the $\mathrm{MBV}$ value of hemp shiv is around 2.07 $\mathrm{g} /\left(\mathrm{m}^{2} . \% \mathrm{RH}\right)$. A slight increase of $\mathrm{MBV}$ is obtained with the coating. Therefore, according to the Nordtest classification, both untreated and treated hemp shiv exhibit excellent hydric regulation properties, which remain in the level of moisture buffering $(\mathrm{MBV}>2$ ). The research undertaken by Lozhechnikova et al. has shown that the use of wax particles can preserved moisture buffering ability, and may even deliver improvements, describing an example where the MBV was increased to 1.08 and 1.09 on the radial and tangential surfaces respectively, whereas solid wax films are seen to reduce the moisture buffering ability to limited levels $(0.2<\mathrm{MBV}<0.5)$ or even less ${ }^{30}$. In addition, Lozhechnikonva et al. also reported CA values around 160 degrees and MBV around 1.4 using wax particles with layer-by-layer deposition $^{31}$. From these data, It can be seen that particles of functionalised silica or wax offer substantial improvements in the preservation of the efficiency of wood as a natural moisture buffering material when compared to the performances offered by a continuous wax layer. Similarly, commercial treatments such as linseed oil coating and lacquer coating were also found to decrease moisture buffering to moderate or limited levels. The hydrophobic coatings form an impermeable barrier on the hemp shiv that water droplets cannot penetrate. The noticeable advantage of 
the functionalised silica NPs or wax particles is that they are too small to block the primary pores found in the hemp shiv, therefore water vapour can permeate freely, thus allowing the excellent moisture buffering properties of the underlying material to be retained.

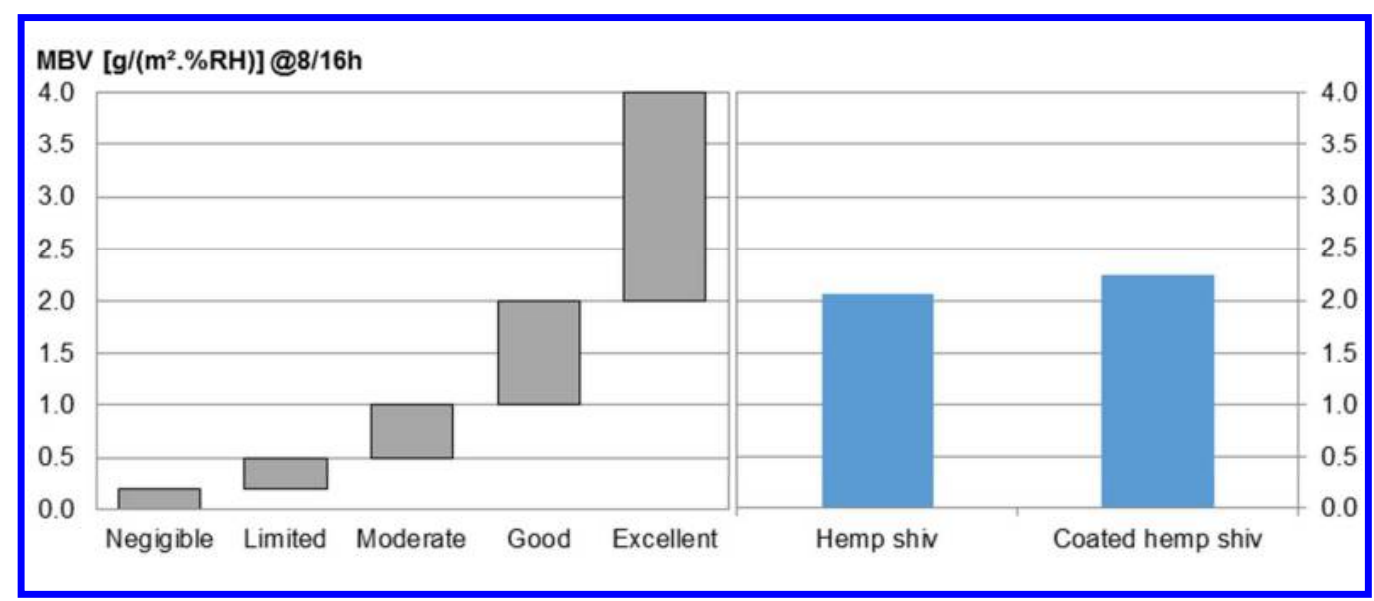

Figure 12: Practical moisture buffer value classes and moisture buffer values of hemp shiv and coated hemp shiv

\section{Conclusions}

In conclusion, this work has shown that a simple dip-coating method can create a coating of functionalised silica nanoparticles which enables the fabrication of hydrophobic hemp shiv. Uniform and multiple layers of silica coating were achieved on the surface of both external and internal voids of hemp shiv by using a dipcoating method. FTIR analysis showed that trimethylsilyl groups were introduced onto the surface of silica nanoparticles and replaced the hydroxyl groups $(-\mathrm{OH})$. The specific surface areas of silica NPs decreased after modification by HMDS. The surface modification decreased the moisture adsorption content and reduced the 
level of hysteresis shown between the isotherms for adsorption and desorption. In addition, the results revealed that the functionalised silica nanoparticles were deposited uniformly over the hemp shiv surface with multiple layers. The initially hydrophilic hemp surface was made hydrophobic with the silica treatment, and exhibited a water contact angle of $120^{\circ}$ or higher. The functionalised silica coating deposited on the hemp shiv surface led to a reduction in water absorption of $150 \%$ of the mass of the hemp shiv (from $400 \%$ for the untreated shiv to $250 \%$ for the treated shiv) whilst still retaining excellent moisture buffering properties of the hemp shiv.

\section{Competing interest}

We declare we have no competing interests.

\section{Acknowledgements}

The work presented here was carried out under the ISOBIO project, with has received funding from the European Union's Horizon 2020 research and innovation programme, under grant agreement No. 636835.

\section{Supporting Information}

Durability test of silica-coating on the hemp shiv

\section{References}

1. Collet, F.; Pretot, S., Thermal conductivity of hemp concretes: Variation with formulation, density and water content. Construction and Building Materials 2014, 65, 612-619, DOI 10.1016/j.conbuildmat.2014.05.039. 
2. Lawrence, M.; Fodde, E.; Paine, K.; Walker, P. In Hygrothermal Performance of an Experimental Hemp-Lime Building, Key Engineering Materials, Trans Tech Publ: 2012; pp 413-421, DOI 10.1016/j.conbuildmat.2012.04.123.

3. Kinnane, O.; Reilly, A.; Grimes, J.; Pavia, S.; Walker, R., Acoustic absorption of hemp-lime construction. Construction and Building Materials 2016, 122 (Supplement C), 674-682, DOI 10.1016/j.conbuildmat.2016.06.106.

4. Latif, E.; Tucker, S.; Ciupala, M. A.; Wijeyesekera, D. C.; Newport, D., Hygric properties of hemp bio-insulations with differing compositions. Construction and Building Materials 2014, 66, 702711, DOI 10.1016/j.conbuildmat.2014.06.021.

5. Collet, F.; Pretot, S., Experimental highlight of hygrothermal phenomena in hemp concrete wall. Building and Environment 2014, 82, 459-466, DOI 10.1016/j.buildenv.2014.09.018.

6. Collet, F.; Chamoin, J.; Pretot, S.; Lanos, C., Comparison of the hygric behaviour of three hemp concretes. Energv and Buildings 2013, 62, 294-303, DOI 10.1016/j.enbuild.2013.03.010.

7. Celia, E.; Darmanin, T.; Taffin de Givenchy, E.; Amigoni, S.; Guittard, F., Recent advances in designing superhydrophobic surfaces. Journal of Colloid and Interface Science 2013, 402, 1-18, DOI 10.1016/j.jcis.2013.03.041.

8. Bellanger, H.; Darmanin, T.; Taffin de Givenchy, E.; Guittard, F., Chemical and Physical Pathways for the Preparation of Superoleophobic Surfaces and Related Wetting Theories. Chemical Reviews 2014, 114 (5), 2694-2716, DOI 10.1021/cr400169m.

9. Gao, J.; Huang, X.; Xue, H.; Tang, L.; Li, R. K. Y., Facile preparation of hybrid microspheres for super-hydrophobic coating and oil-water separation. Chemical Enqineering Journal 2017, 326 (Supplement C), 443-453, DOI 10.1016/j.cej.2017.05.175.

10. Maleki, H., Recent advances in aerogels for environmental remediation applications: A review. Chemical Enqineering Journal 2016, 300 (Supplement C), 98-118, DOI 10.1016/j.cej.2016.04.098.

11. Saha, P.; Chowdhury, S.; Manna, S.; Roy, D.; Adhikari, B.; Thomas, S., New Biobased Surface Treatment to Improve Strength and Durability of Bombax ceiba. 2016.4 (1).76-84.DOI 10.1021/acssuschemeng.5b01057.

12. Chang, H.; Tu, K.; Wang, X.; Liu, J., Facile Preparation of Stable Superhydrophobic Coatings on Wood Surfaces using Silica-Polymer Nanocomposites. BioResources 2015, 10 (2), 2585-2596, DOI 10.15376/biores.10.2.2585-2596.

13. Lee, J. H.; Kim, D. H.; Han, S. W.; Kim, B. R.; Park, E. J.; Jeong, M.-G.; Kim, J. H.; Kim, Y. D., Fabrication of superhydrophobic fibre and its application to selective oil spill removal. Chemical Enaineerina Journal 2016, 289 (Supplement C), 1-6, DOI 10.1016/j.cej.2015.12.026.

14. Li, C.; Sun, Y.; Cheng, M.; Sun, S.; Hu, S., Fabrication and characterization of a TiO2/polysiloxane resin composite coating with full-thickness super-hydrophobicity. Chemical Enaineerina Journal 2018, 333 (Supplement C), 361-369, DOI 10.1016/j.cej.2017.09.165.

15. Liu, C.; Wang, S.; Shi, J.; Wang, C., Fabrication of superhydrophobic wood surfaces via a solution-immersion process. Applied Surface Science 2011, 258 (2), 761-765, DOI 10.1016/j.apsusc.2011.08.077.

16. Lu, Y.; Feng, M.; Zhan, H., Preparation of SiO2-wood composites by an ultrasonic-assisted sol-gel technique. Cellulose 2014, 21 (6), 4393-4403, DOI 10.1007/s10570-014-0437-6.

17. Nadargi, D. Y.; Gurav, J. L.; El Hawi, N.; Rao, A. V.; Koebel, M., Synthesis and characterization of transparent hydrophobic silica thin films by single step sol-gel process and dip coating. Journal of Allovs and Compounds 2010, 496 (1-2), 436-441, DOI 10.1016/j.jallcom.2010.01.157.

18. Peng, Y.-T.; Lo, K.-F.; Juang, Y.-J., Constructing a Superhydrophobic Surface on Polydimethylsiloxane via Spin Coating and Vapor-Liquid Sol-Gel Process. Lanamuir 2010, 26 (7), 5167-5171, DOI 10.1021/la903646h@proofing.

19. Bourebrab, M.; Durand, G.; Taylor, A., Development of Highly Repellent Silica Particles for Protection of Hemp Shiv Used as Insulation Materials. Materials 2018, 11 (1), 4, DOI 10.3390/ma11010004. 
20. Hussain, A.; Calabria-Holley, J.; Schorr, D.; Jiang, Y.; Lawrence, M.; Blanchet, P., Hydrophobicity of hemp shiv treated with sol-gel coatings. Applied Surface Science 2018, 434, 850860, DOI 10.1016/j.apsusc.2017.10.210.

21. Bergna, H. E., The Colloid Chemistry of Silica. American Chemical Society: 1994; Vol. 234, p 724, DOI 10.1021/ba-1994-0234.

22. Suratwala, T. I.; Hanna, M. L.; Miller, E. L.; Whitman, P. K.; Thomas, I. M.; Ehrmann, P. R.; Maxwell, R. S.; Burnham, A. K., Surface chemistry and trimethylsilyl functionalization of Stöber silica sols. Journal of Non-Crvstalline Solids 2003, 316 (2), 349-363, DOI 10.1016/S0022-3093(02)01629-0.

23. PHILIPAVIČIUS, J.; Kazadojev, I.; Beganskiene, A.; A., M.; Sirutkaitis V. Kareiva, A., Hydrophobic Antireflective Silica Coatings via Sol-gel Process. Materials Science 2008, 14 (4), $283-$ 287.

24. Qiu, X.; Li, Z.; Li, X.; Zhang, Z., Flame retardant coatings prepared using layer by layer assembly: A review. Chemical Enqineering Journal 2018, 334 (Supplement C), 108-122, DOI 10.1016/j.cej.2017.09.194.

25. Machovsky, M.; Kuritka, I.; Bazant, P.; Vesela, D.; Saha, P., Antibacterial performance of ZnObased fillers with mesoscale structured morphology in model medical PVC composites. Materials Science and Enqineerina: C 2014, 41, 70-77, DOI 10.1016/j.msec.2014.04.034.

26. Rassam, G.; Abdi, Y.; Abdi, A., Deposition of TiO2 nano-particles on wood surfaces for UV and moisture protection. Journal of Experimental Nanoscience 2012, 7 (4), 468-476, DOI 10.1080/17458080.2010.538086.

27. Graziola, F.; Girardi, F.; Di Maggio, R.; Callone, E.; Miorin, E.; Negri, M.; Müller, K.; Gross, S., Three-components organic-inorganic hybrid materials as protective coatings for wood: Optimisation, synthesis, and characterisation. Proaress in Oraanic Coatings 2012, 74 (3), 479-490, DOI 10.1016/j.porgcoat.2012.01.013.

28. Tshabalala, M. A.; Kingshott, P.; VanLandingham, M. R.; Plackett, D., Surface chemistry and moisture sorption properties of wood coated with multifunctional alkoxysilanes by sol-gel process. Journal of Applied Polvmer Science 2003, 88 (12), 2828-2841, DOI 10.1002/app.12142.

29. Tang, B.; Wang, J.; Xu, S.; Afrin, T.; Tao, J.; Xu, W.; Sun, L.; Wang, X., Function improvement of wool fabric based on surface assembly of silica and silver nanoparticles. Chemical Engineering Journal 2012, 185-186 (Supplement C), 366-373, DOI 10.1016/j.cej.2012.01.082.

30. Lozhechnikova, A.; Vahtikari, K.; Hughes, M.; Österberg, M., Toward energy efficiency through an optimized use of wood: The development of natural hydrophobic coatings that retain moisture-buffering ability. Enerav and Buildinas 2015, 105 (Supplement C), 37-42, DOI 10.1016/j.enbuild.2015.07.052.

31. Lozhechnikova, A.; Bellanger, H.; Michen, B.; Burgert, I.; Österberg, M., Surfactant-free carnauba wax dispersion and its use for layer-by-layer assembled protective surface coatings on wood. Applied Surface Science 2017, 396, 1273-1281, DOI 10.1016/j.apsusc.2016.11.132.

32. Rode, C., Moisture buffering of building materials. Department of Civil Engineering, Technical University of Denmark BYG DTU-126 Report 2005.

33. Jiang, Y.; Lawrence, M.; Ansell, M. P.; Hussain, A., Cell wall microstructure, pore size distribution and absolute density of hemp shiv. Roval Societv Open Science 2018, 5 (4), DOI 10.1098/rsos.171945.

34. Stöber, W.; Fink, A.; Bohn, E., Controlled growth of monodisperse silica spheres in the micron size range. Journal of Colloid and Interface Science 1968, 26 (1), 62-69, DOI 10.1016/00219797(68)90272-5.

35. S., H. C. A.; Andrew, N.; Gary, N., The water vapor sorption behavior of natural fibers. Journal of Applied Polvmer Science 2009, 112 (3), 1524-1537, DOI 10.1002/app.29725.

36. Hussain, A.; Calabria-Holley, J.; Jiang, Y.; Lawrence, M., Modification of hemp shiv properties using water-repellent sol-gel coatings. Journal of Sol-Gel Science and Technologv 2018, 86 (1), 187197, DOI 10.1007/s1097. 
37. Collet, F.; Prétot, S.; Lanos, C., Hemp-Straw Composites: Thermal And Hygric Performances. Enerav Procedia 2017, 139, 294-300, DOI 10.1016/j.egypro.2017.11.211.

38. Stetefeld, J.; McKenna, S. A.; Patel, T. R., Dynamic light scattering: a practical guide and applications in biomedical sciences. Biophvsical Reviews 2016, 8 (4), 409-427, DOI 10.1007/s12551016-0218-6.

39. Thommes, M.; Kaneko, K.; Neimark Alexander, V.; Olivier James, P.; Rodriguez-Reinoso, F.; Rouquerol, J.; Sing Kenneth, S. W., Physisorption of gases, with special reference to the evaluation of surface area and pore size distribution (IUPAC Technical Report). In Pure and Applied Chemistry, 2015; Vol. 87, p 1051, DOI 10.1515/ci-2016-0119.

40. Sing, K. S. W.; Everett, D. H.; Haul, R. A. W.; Moscou, L.; Pierotti, R. A.; Rouquerol, J.; Siemieniewska, T., Reporting Physisorption Data for Gas/Solid Systems. In Handbook of Heterogeneous Catalvsis, Wiley-VCH Verlag GmbH \& Co. KGaA: 2008, DOI 10.1002/9783527610044.hetcat0065.

41. Brunauer, S.; Emmett, P. H.; Teller, E., Adsorption of Gases in Multimolecular Layers. Journal of the American Chemical Societv 1938, 60 (2), 309-319, DOI 10.1021/ja01269a023.

42. Takei, T.; Yamazaki, A.; Watanabe, T.; Chikazawa, M., Water Adsorption Properties on Porous Silica Glass Surface Modified by Trimethylsilyl Groups. Journal of Colloid and Interface Science 1997, 188 (2), 409-414, DOI 10.1006/jcis.1997.4777.

43. Zhang, X.; Zheng, F.; Ye, L.; Xiong, P.; Yan, L.; Yang, W.; Jiang, B., A one-pot sol-gel process to prepare a superhydrophobic and environment-resistant thin film from ORMOSIL nanoparticles. $\underline{R S C}$ Advances 2014, 4 (19), 9838-9841, DOI 10.1039/c3ra47185c.

44. Chang, C.-C.; Wu, Y.-T.; Cheng, L.-P., Preparation of HMDS-modified silica/polyacrylate hydrophobic hard coatings on PMMA substrates. Journal of Coatings Technologv and Research 2016, 13 (6), 999-1007, DOI 10.1007/s11998-016-9820-6.

45. He, J.; Li, X.; Su, D.; Ji, H.; Zhang, X.; Zhang, W., Super-hydrophobic hexamethyl-disilazane modified ZrO2-SiO2 aerogels with excellent thermal stability. Journal of Materials Chemistrv $A$ 2016, 4 (15), 5632-5638, DOI 10.1039/c6ta00568c.

46. Esteves, B.; Velez Marques, A.; Domingos, I.; Pereira, H., Chemical changes of heat treated pine and eucalypt wood monitored by FTIR. Maderas. Ciencia v tecnología 2013, 15, 245-258, DOI 10.4067/S0718-221X2013005000020.

47. Rana, R.; Langenfeld-Heyser, R.; Finkeldey, R.; Polle, A., FTIR spectroscopy, chemical and histochemical characterisation of wood and lignin of five tropical timber wood species of the family of Dipterocarpaceae. Wood Science and Technologv 2010, 44 (2), 225-242, DOI 10.1007/s00226-0090281-2.

48. Pandey, K. K., A study of chemical structure of soft and hardwood and wood polymers by FTIR spectroscopy. Journal of Applied Polvmer Science 1999, 71 (12), 1969-1975, DOI 10.1002/(SICI)1097-4628(19990321)71:12<1969::AID-APP6>3.0.CO;2-D.

49. Rosso-Vasic, M.; Spruijt, E.; van Lagen, B.; De Cola, L.; Zuilhof, H., Alkyl-Functionalized OxideFree Silicon Nanoparticles: Synthesis and Optical Properties. Small 2008, 4 (10), 1835-1841, DOI 10.1002/smll.200990114.

50. Bywalez, R.; Karacuban, H.; Nienhaus, H.; Schulz, C.; Wiggers, H., Stabilization of mid-sized silicon nanoparticles by functionalization with acrylic acid. Nanoscale Research Letters 2012, 7 (1), 76, DOI 10.1186/1556-276X-7-76.

51. Zou, J.; Baldwin, R. K.; Pattingrew, K. A.; Kauzlarich, S. M., Solution synthesis of ultrastable luminescent siloxane-coated silicon nanoparticles. Nano Lett 2004, 4, DOI 10.1021/nl0497373. 
2

3

4

5

6

7

8

10

11

12

13

14

15

16

17

18

19

20

21

22

23

24

25

26

27

28

29

30

31

32

33

34

35

36

37

38
39

40

41

42

43

44

45

46

47

48

49

50

51

52

53

54

55

56

57

58

59 


\section{For Table of Contents Use Only:}

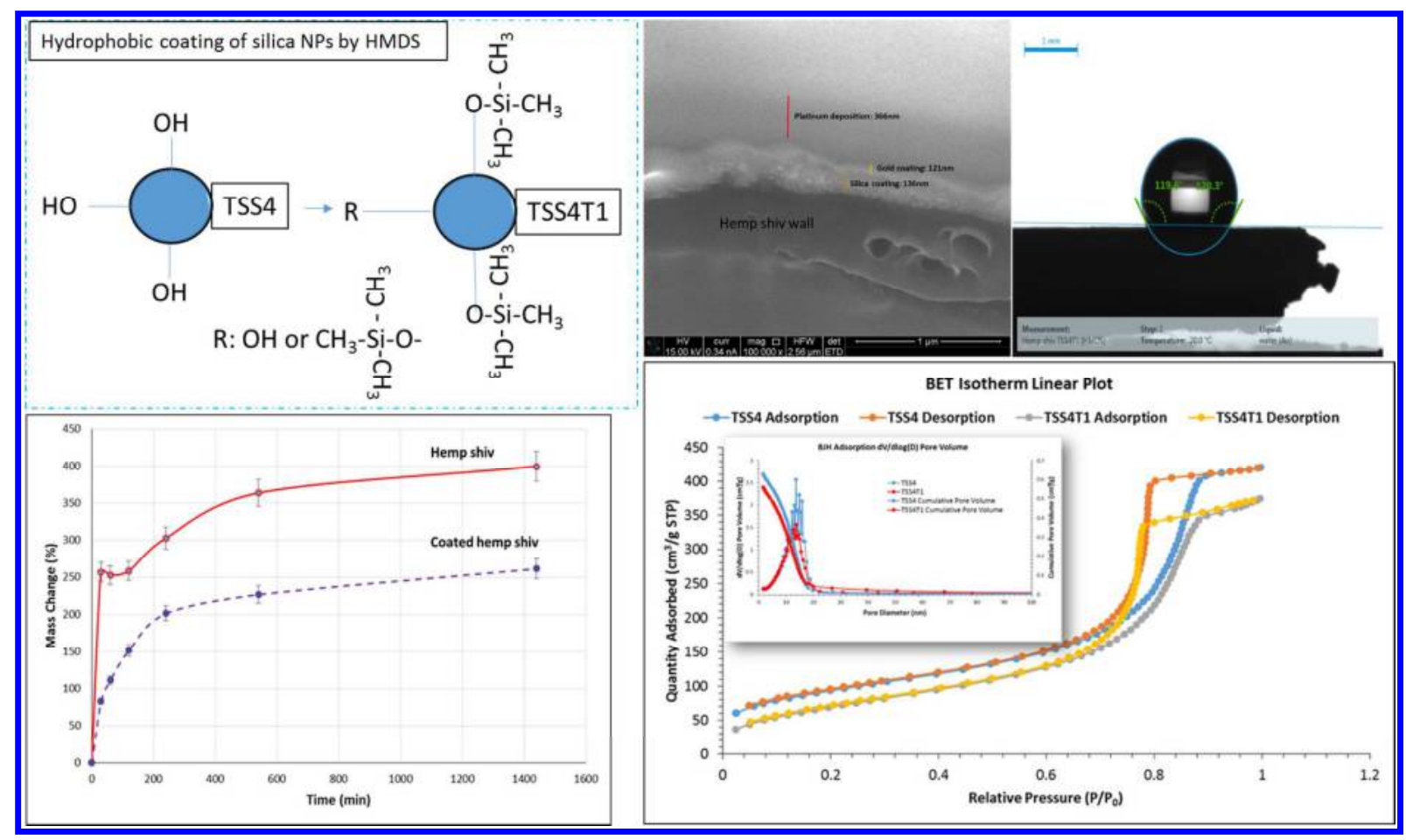

Synopsis:

This work develops bio-based materials for construction to offer a number of benefits as well as desirable environmental characteristics such as sustainability and renewability. 